\title{
Технология производства тяжелой воды вымораживанием
}

\section{Л. Ф. Смирнов}

Одесская национальная академия пищевых технологий, ул. Канатная 112, г. Одесса, 65039, Украина

\begin{abstract}
Предлагается вымораживающая технология производства тяжелой воды. Технология основана на значительном коэфрициенте разделения изотопов водорода в процессах вымораживания. Используется принцип колоночной кристаллизации и плавления льда по высоте ректификационной колонны, позволяющий при еще не очень больщой высоте колонны получать высокую концентрацию дейтерия. Рассмотрены физическая и математическая модели колоночной кристаллизации с определением методики расчета концентрации дейтерия по высоте колонны. Особенно перспективна технология при комбинировании производства тяжелой воды с опреснением-разделением соленой воды вымораживанием, когда уже полученный чистый лед опреснителя еще до его расплавления используется попутно в концентраторе тяжелой воды, что существенно уменьшает энерго и
\end{abstract} капзатраты ее производства.

Ключевые слова: Дейтерий; Тяжелая вода; Вымораживание; Опреснение.

\section{Технологія виробництва важкої води виморожуванням}

\section{Л. Ф. Смірнов}

Одеська національна академія харчових технологій, вул. Канатна 112, м. Одесса, 65039, Україна

\begin{abstract}
Пропонується технологія виробництва важкої води виморожуванням. Технологія заснована на значному коефріцієнті поділу ізотопів водню в процесах виморожування. Використовується принцип колоночноі кристалізації і плавлення льоду по висоті колони ректифікації, що дозволяє при ще не дуже великій висоті колони отримувати високу концентрацію дейтерію. Розглянуто фрізичну і математичну моделі колоночної кристалізації з визначенням методики розрахунку концентрації дейтерію по висоті колони. Особливо перспективна технологія при комбінуванні виробництва важкої води опрісненням-поділом солоної води виморожуванням, коли вже отриманий чистий лід опріснювача ще до його розплавлення використовується попутно в концентраторі важкої води, що істотно зменшує енергетичні та капітальні заmрати ії виробництва.
\end{abstract}

Ключові слова: Дейтерій; Важка вода; Виморожування; Опріснення.

DOI: http://dx.doi.org/10.15673/ret.v53i1.546

(C) The Author(s) 2017. This article is an open access publication

This work is licensed under the Creative Commons Attribution 4.0 International License (CC BY) http://creativecommons.org/licenses/by/4.0/

\section{1. Введение}

Тяжелая вода - важное промышленное сырье для атомной энергетики, эффективный замедлитель быстрых нейтронов. При термоядерном распаде 1 г дейтерия дает в 10 млн. раз больше энергии, чем 1 г угля при сгорании.

Дейтерий расматривается как оружейное стратегическое сырье, использующее энергию реакции ядерного синтеза, позволяющее в разрушительных военных целях получать много энергии. Фазовые переходы (кристаллизация, кипение) показывают эффект фракционирования изотопов, в том числе водорода - дейтерия и трития $[1,8]$. Наши эксперименты продемонстрировали рост концентрации дейтерия при последовательности кристаллизации газогидратов фреона-12 и их плавлении, когда продуктом последующего гидратообразования служил расплав гидратов предыдущего процесса [1]. Для разделения изотопов наряду с другими методами применяется метод колоночной кристализации, описанный в работах $[2,5]$.

Наиболее разработан этот принцип для разделения эвтектикообразующих растворов. 
Изучены, например, системы бензол-циклогексан (в безотборном режиме [2] и с отбором продукта [3], лед - раствор $\mathrm{NaCl}$. Примерами разделения твердых растворов служат системы м-хлорнитробензол м-бромнитробензол и оксобензолстилбен (малые и большие коэффициенты разделения соответственно, безотборный режим [5].

Лед после вымораживающих опреснителейконцентраторов-разделителей соленой воды возможно использовать для концентрирования тяжелой воды. Особенно обогащаются (примерно на $15 \div 25 \%$ массовых) дейтерием первые порции льда при вымораживании воды. Анализы образцов воды Черного моря (до и после вымораживания), выполненные в лаборатории геохимии изотопов и геохронологии (Геологический институт РАН, Москва) показали увеличение концентрации тяжелого изотопного состава водорода в промиллях относительно стандарта V-SMOW примерно на 25\%.

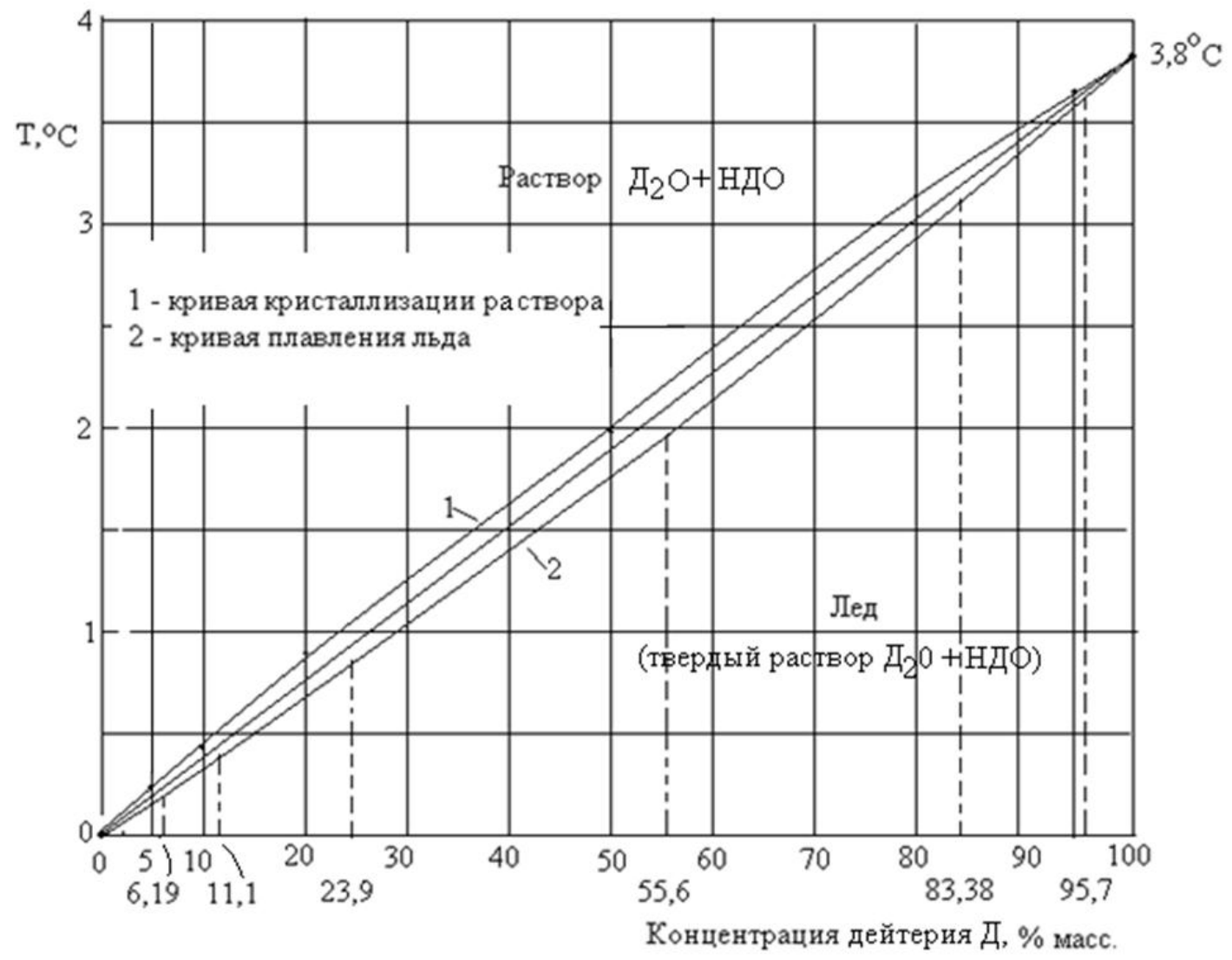
Рисунок 1 - Изотопное равновесие системы $\mathrm{H}_{2} \mathrm{O}+Д_{2} \mathrm{O}+\mathrm{H}$ ДО
на диаграмме Температура-Состав $\mathrm{T}-\mathrm{X}$

Концентрация тяжелых изотопов водорода (дейтерия и трития) в смеси Д $О+\mathrm{HДO} \mathrm{в} \mathrm{морской}$ воде около 0,015\% массовых (есть воды и с концентрацией 0,016\%).

Расход в ВОР-1000 воды в количестве 1000 т/сут имеет тяжелых изотопов водорода 1000·0,016/100 = = 0,16 т/сут. Эта вода после опреснения вымораживанием облегчена по дейтерию на $25 \%$. Т.е. при первом же льдообразовании она потеряла дейтерия 0,16·0,25 = 0,04 т/сут. При отборе первого льда (не более 5\% от производительности по воде), не направляемого на питьевые или поливные цели, в него войдет 0,04·0,05 =0,002 т дейтерия/сут. Если его направить из опреснителя (без переделок опреснителя) в ректификационную колонну РК, то можно извлечь дейтерия в РК около 80\% (20\% на различные неучтенные потери), при этом выход тяжелой воды будет 0,002·0,8·5 = 0,008 т/сут или $0,008 \cdot 365=2,92$ т/год тяжелой воды. Доход - около $2,92 \cdot 10^{3} \cdot 500=1,46 \mathrm{млн.} \mathrm{дол/год.}$

При незначительной переделке ВОР (а именно, конденсатор хладоагента из кармана СПК переставляется в верхний карман РК; весь лед после СПК направляется В РК, потери исключаются) возможно извлечь дейтерия около 0,16.0,25 = = 0,04 т/сут или 0,04.365 = 14,6 т/год. Если принять, что тяжелая вода будет только в форме $\mathrm{D}_{2} \mathrm{O}$ (молекулярная масса 4+16=20 кг/кмоль), то перерасчет массы дейтерия на массу тяжелой воды (с учетом только легкого изотопа кислорода ${ }^{16} \mathrm{O}$ ) дает значения: $0,04 \cdot 20 / 4=0,2$ т тяжелой воды/сут или 0,2·365 = 73 т тяжелой воды/год . 
При мировой цене тяжелой воды в 500 дол/кг дополнительный доход составит около $73 \cdot 10^{3} \cdot 500=$ = 36,5 млн. дол/год.

\section{2 Технология}

Вслед за рассмотренной нами ранее системы вода - газовый гидрат [1,8], целесообразно рассмотреть также систему лед - вода, представляющую во льду твердый раствор $\mathrm{HDO}+\mathrm{D}_{2} \mathrm{O}$ в $\mathrm{H}_{2} \mathrm{O}$. По аналогии c [8] представлена математическая модель для отборного режима (т.е. с выдачей концентрата $\mathrm{D}_{2} \mathrm{O}$ ). Физическая модель колоночной кристаллизации представлена на рисунке 2. В кристаллизатор 1 поступает обычная вода $\mathrm{c}$ расходом $\mathrm{F} n$ концентрацией дейтерия $\mathrm{Y}_{\mathrm{F}} \approx 0,16 \cdot 10^{-3}$ кг дейтерия/кг воды. После образования «первого» льда из кристаллизатора выводятся вода $L_{s} c$ незначительно уменьшенной концентрацией дейтерия $Y_{S} \leq Y_{F}$ и кристаллы льда с расходом С, транспортируемые в колонне 2 шнеком. Концентрация дейтерия X в них по высоте колонны переменная. Противоточно льду опускается орошающая вода L, имеющая переменую по высоте колонны концентрацию дейтерия Y.

В плавителе 3 лед плавится с выделением концентрата дейтерия. Часть его выводят в виде продукта с массовым расходом $\mathrm{L}_{\mathrm{e}}$ и концентрацией $\mathrm{Y}_{\mathrm{e}}$ другая часть в виде флегмы опускается в колонне противоточно льду для ректификации дейтерия. Транспорт дейтерия в колонне осуществляется диффузией в жидкой фазе и массопередачей из твердой фазы В жидкую [5] в результате последовательных процессов плавления и образования льда. В виду более высокой температуры льдообразования дейтериевой воды по сравнению с температурой льдообразования протиевой воды при плавлении в жидкость переходят в первую очередь молекулы протия, при образовании льда в структуру его переходят в первую очередь молекулы дейтерия.

В результате последовательности процессов фракционированного образования и плавления льда и массопередачи молекул тяжелой воды в твердую фазу по высоте колонны происходит постепенное обогащение льда дейтерием при его движении вверх. При этом по высоте колонны поддерживается разность температур, равная $4 \div 5^{\circ} \mathrm{C}$. Плавитель имеет

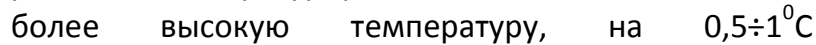
превышающую равновесную температуру плавления дейтериевого льда, а температура кристаллизатора примерно на $0,5 \div 1^{0} \mathrm{C}$ ниже равновесной температуры образования льда из нормальной воды. Притоки тепла из окружающей среды в колонну, а также передача тепла вдоль колонны по валу шнека должны быть сведены к минимуму.

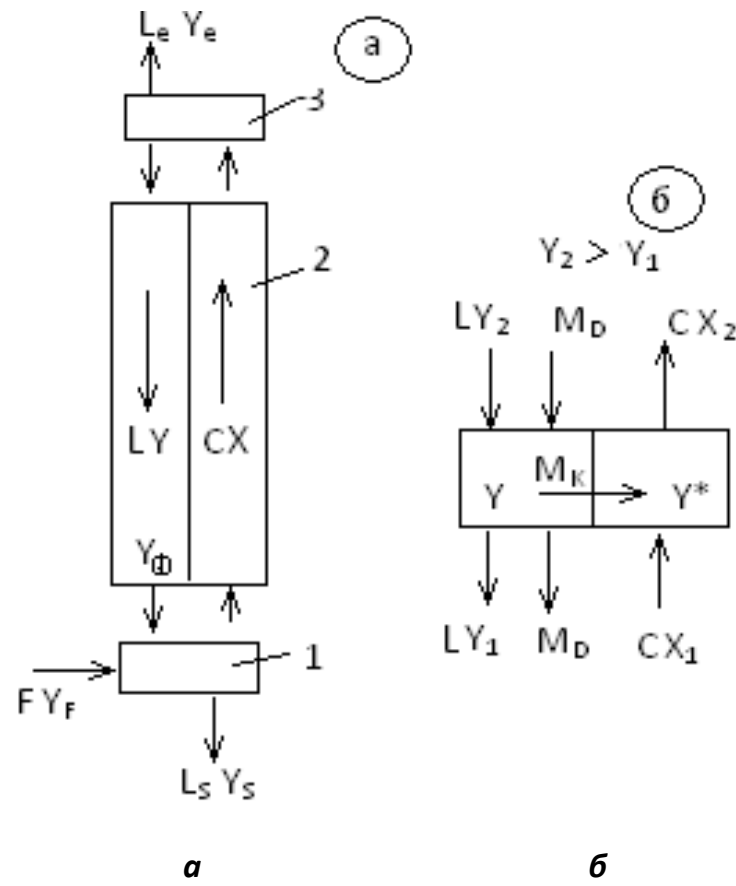

Рисунок 2 - Физическая модель колоночной кристаллизации льда

a - схема установки для разделения льда (HDO- $\mathrm{D}_{2} \mathrm{O}$ в $\mathrm{H}_{2} \mathrm{O}$ в отборном режиме),

б-схема потоков в системе жидкость - лед.

1 - кристаллизатор, 2 - ректифрикационная колонна, 3 -плавитель.

Скорость массопередачи $\mathrm{M}_{\mathrm{k}}$ (кг/с) пропорциональна отклонению от равновесия в жидкой фазе $\left(\mathrm{Y}^{*}\right)$, где $\mathrm{Y}$ и $\mathrm{Y}^{*}$ - концентрации дейтерия в жидкой фазе - действительная и равновесная концентрация дейтерия в твердом льде (кг/кг):

$$
\mathrm{M}_{\mathrm{K}}=\operatorname{KaA\rho }\left(\mathrm{Y}-\mathrm{Y}^{*}\right) \Delta \mathrm{z}
$$

где К - коэффициент массопередачи, м/с; а поверхность массопередачи между кристаллами и орошающей жидкостью на единицу объема колонны, м $^{-1}$; - поперечное сечение колонны, измеренное перпендикулярно потокам твердой фазы и жидкости, м²; $\rho$ - плотность жидкой фазы,

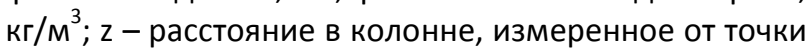
подачи кристаллов в колонну и равное длине винтовой траектории движения потоков, м.

Скорость полной диффузии дейтерия в жидкой фазе определяется выражением

$$
M_{D}=D \rho A \varepsilon(d Y / d z),
$$

принципиальная особенность которого - отсутствие привычного знака (-), так как выбранное направление оси z в системе противоположно диффузии дейтерия $\left(\mathrm{Y}_{2}>\mathrm{Y}_{1}\right)$ в потоке жидкой фазы L (рис. 2). Здесь D - коэффициент диффузии, $\mathrm{m}^{2} / \mathrm{c} ; \varepsilon-$ объемная доля орошающей жидкости. 
При составлении математической модели приняты следующие упрощающие допущения:

1. Изменение в составе кристалла льда контролируется скоростьи массопередачи из твердой фазы в жидкую. Предполагается, что ни диффузия в твердой фазе, ни теплорпередача не ограничивают процесса.

2. Теплофизические и транспортные свойства по высоте колонны постоянны, т.е. постоянны K, $D, \rho, \varepsilon$, A, a, $\alpha_{i}, Q$.

3. Расход каждой фазы в любом сечении колонны постоянен.

4. Скорости образования и плавления льда равны по величине, противоположны по направлению и не зависят от положения в колонне. Теплота образования и теплота плавления льда регенерируются.

Для установившегося режима с отбором продукта составляется система из 4-х уравнений с 4-мя переменными Y, Y*, X, z. Массовый баланс дифференциального элемента колонны по дейтерию в жидкой фазе (рисунок 2б).

$$
L(d Y / d z)-K a A \rho\left(Y-Y^{*}\right)+D \rho A \varepsilon\left(d^{2} Y / d z^{2}\right)=0
$$

С целью значительного упрощения модели диффузионным членом ввиду его незначительности пренебрегаем [3]. Массовый баланс верхней части колонны по дейтерию

$$
C X-L X-D \rho A \varepsilon(d Y / d z)-L_{e} X_{e}
$$

Полный баланс колонны для условия отбора концентрата дейтерия

$$
\mathrm{L}-\mathrm{C}+\mathrm{L}_{\mathrm{e}}=0
$$

Уравнение фазового равновесия твердый лед жидкая фаза устанавливает связь между содержанием дейтерия во льду $X$ и равновесной концентрацией дейтерия в жидкой фазе $\mathrm{Y}^{*}$.

Коэффициент разделения $\alpha_{\mathrm{i}}$ :

$$
\alpha_{i}=\frac{\frac{x}{[1-x)}}{\frac{\gamma-}{[1-\gamma-\rangle}}
$$

или

$$
X=\alpha_{i} Y^{*} /\left[1-Y^{*}\left(1-\alpha_{i}\right)\right]
$$

Здесь X, Y - массовые концентрации дейтерия в обогащенной и обедненной воде соответственно.

Для малых концентраций

$$
X=\alpha_{i} Y^{*}
$$

Принимая по результатам изотопного анализа льда $\alpha_{i}=1,255$ и считая его одинаковым по всей длине «рыбки» (рисунок 1), по уравнению (6) имеем:

\begin{tabular}{|c|c|c|c|c|c|c|c|}
\hline $\begin{array}{c}\text { Y, } \\
\% \text { мacc. }\end{array}$ & 1 & 5 & 10 & 20 & 50 & 80 & 95 \\
\hline $\begin{array}{c}\mathrm{X}, \\
\% \text { мacc. }\end{array}$ & 1,25 & 6,19 & 11,1 & 23,9 & 55,6 & 83,38 & 95,7 \\
\hline
\end{tabular}

Пример расчета:

Примем $Y=50 \%$ :

$$
X=\frac{\alpha_{i} Y}{\left[1-Y\left(1-\alpha_{i}\right)\right.}=\frac{1,255 \cdot 0,5}{[1-[, 5(1-1,255)]}=0,556 \text { или } 55,6 \% .
$$

При комбинировании уравнений (3), (4) и (7) получаем

$$
\left[L C \alpha_{i} /(K a A \rho)+D \rho A \varepsilon\right](d Y / d z)-\left(C \alpha_{i}-L\right) Y=-L_{e} Y_{e}
$$

Это линейное неоднородное дифференциальное уравнение при граничных условиях $\mathrm{z}=0, \mathrm{Y}=\mathrm{Y}_{\phi}$ (концентрация дейтерия в орошающей воде перед колонной на отметке $z=0$ ) имеет решение

$$
\left(Y-Y_{p}\right) /\left(Y_{\phi}-Y_{p}\right)=\exp [-(z / H)],
$$

где $Y_{p}=\frac{l_{\theta} Y \theta}{\left(\left(\alpha_{i}-1\right)+l_{p}\right.}$,

$$
H=-\frac{1}{C\left(\alpha_{i}-1\right)+i_{p}}\left[D \rho A \varepsilon+\frac{\alpha_{i}\left(C^{2}-i_{8} C\right)}{K_{a A p}}\right]
$$

$\left(a_{i}-1\right)=\left(\frac{x}{\gamma^{*}}-1\right)=\frac{x-\gamma^{*}}{\gamma^{-}}-$это превышение концентрации дейтерия во льду над его равновесной концентрацией в исходной воде, отнесенное к равновесной концентрации дейтерия в исходной воде.

Согласно уравнениям (9) и (10), эффект разделения (увеличение концентрации Y) пропорционален высоте колонны z и усиливается с уменьшением коэффициента сепарации $\mathrm{H}$ при постоянных $\mathrm{Y}_{\phi}$ и $\mathrm{Y}_{\mathrm{p}}$. При постоянной скорости вращения шнека и постоянных $A, \rho, \varepsilon$ и $L_{e}$ величина $H$ определяется $C, D$, $\mathrm{Ka}, \alpha_{\mathrm{i}}$.

Значение Н увеличивается с возрастанием коэффициента диффузии D и уменьшается с увеличением коэффициентов массопередачи Ка и разделения $\alpha_{i}$. Если С увеличивается, то величина $1 /\left[C\left(a_{i}-1\right)+L_{\theta}\right]$ уменьшается, но увеличивается величина $\alpha_{i}\left(C^{2}-L_{\theta} C\right)$.

При малых значениях С главным является коэффициент диффузии D и при этом коэффициент сепарации Н уменьшается. Однако, когда С становится больше, эффект $\mathrm{C}^{2}$ увеличивает $\mathrm{H}$.

Решение уравнения массопередачи (9) для твердого раствора одинаково по форме с аналогичным уравнением Генри и Пауэрса $\left(Y-Y_{p}\right) /\left(Y_{\phi}-Y_{p}\right)=e^{-z / H}$ для эвтектикообразующего раствора [3].

Принципиальные отличия следующие:

1. Уравнение из работы [3] показывает распределение концентрации примеси, а не продукта, по высоте колонны (например, примесь - соль, продукт - пресная вода), в то время как уравнение (9) для твердого раствора показывает распределение концентрации по высоте колонны полезного продукта дейтерия. 
По этой причине решение для твердого раствора принципиально отличается знаком показателя экспоненты.

Для эвтектикообразующего раствора справедлив знак (-), для твердого раствора (+). Соответственно изменяется график решения уравнения массопередачи (рис. 3).

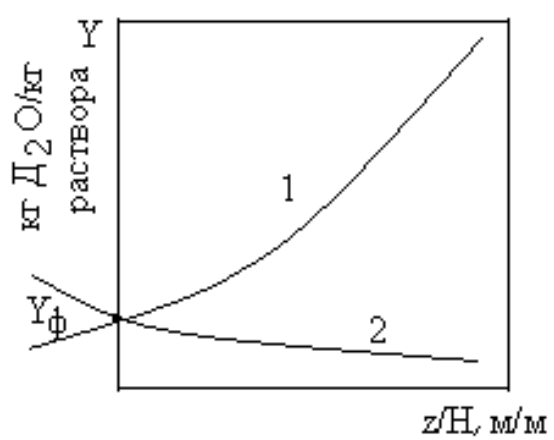

Рисунок 3 - Графики массопередачи для твердого (1) и эвтектикооразующего (2) раство-

$$
1-Y=\left(Y_{\Phi}-Y_{P}\right) e^{+z / H}+Y_{p} ; 2-Y=\left(Y_{\Phi}-Y_{P}\right) e^{-z / H}+Y_{p} .
$$

2. Для эвтектикообразующего раствора массопередача осуществляется на границе жидкой и твердой фаз (последняя - постоянный состав), для твердого раствора массопередача протекает при фазовых переходах - кристаллизации и плавления твердой фазы, имеющей вследствие фракционирования по высоте колонны переменный состав.

Если для случая твердого раствора отнести знак (-) к коэффициенту сепарации $\mathrm{H}$, то формализованное уравнение (9) пригодно для расчета массопередачи в эвтектикообразующих и твердых растворах. Зависимость (7), в общем, может быть и нелинейной. При малой величине диффузионной составляющей в выражении для Н (что имеет место в эвтектикообразующей системе лед - рассол [4]) нет смысла увеличивать площадь сечения А в колонне постоянного диаметра и высоты путем, например, увеличения шага шнека s, поскольку в этом случае результирующее уменьшение Н полностью нейтрализуется уменьшением z, так что величина z/H в итоге не изменяется. Замена колонны со шнеком просто колонной ведет к проигрышу из-за снижения величины $\mathrm{z} / \mathrm{H}$.

В выражении (9) большое значение при разделении имеет разность $Y_{\phi}-Y_{p}$. При малых и больших концентрациях дейтерия, близких к 0 и 1, эта разность мала, что обусловливает сравнительно малую разделяющую способность колоночной кристаллизации в этих областях концентраций. Например, расчет колонны по концентрированию дейтерия показывает увеличение концентрации дейтерия из природной воды в колонне высотой $\mathrm{h}=2$ м в 37 раз (от 0,16 до 0,59\%), в то время как ректификация в областях кон- центраций $0,2 \div 0,8$ показывает эффект по крайней мере на порядок больший [5].

Коэффициент массопередачи в процессах кристаллизации и плавления кристаллов льда принят в первом приближении по опытным данным Гейтса и Пауэрса, $\mathrm{K}=0,071 \cdot 10^{-5} \mathrm{~m} / \mathrm{c}$ для аналогичного процесса фракционного разделения (многократные кристаллизация-плавление по высоте колонны) твердого раствора кристаллов м-хлорнитробензола - м-бромнитробензола в шнековой колонне, имеющего [5, с.651] так же как и раствор $\mathrm{H}_{2} \mathrm{O}-Д_{2} \mathrm{O}$ малый фактор разделения. Из приведенного ниже сравнения значений коэффициентов массопередачи $\mathrm{K}$, диффузии D из различных источников [5] видно, что выбранное значение К наименьшее.

\begin{tabular}{|c|c|c|c|c|c|c|c|c|c|}
\hline $\begin{array}{c}\mathrm{D} \cdot 10^{3} \\
\left(\mathrm{M}^{2} / \mathrm{c}\right)\end{array}$ & 46 & 42 & 17 & 15 & 13 & $\begin{array}{c}\text { от 5 } \\
\text { до } \\
300\end{array}$ & - & - & $\begin{array}{c}\text { от } 8 \\
\text { до 26 }\end{array}$ \\
\hline $\begin{array}{c}\mathrm{K} \cdot 10^{5} \\
(\mathrm{M} / \mathrm{c})\end{array}$ & 0,44 & 0,071 & 0,075 & 0,26 & 0,64 & - & $\begin{array}{c}\text { от 2 } \\
\text { до 5 }\end{array}$ & $\begin{array}{l}\text { от 2 } \\
\text { до 3 }\end{array}$ & - \\
\hline
\end{tabular}

Считая, что средний эквивалентный диаметр кристаллов льда $\mathrm{d}_{\mathrm{cp}}=10^{-4} \mathrm{M}$, их удельная поверхность определяется по формуле $\mathrm{a}=6(1-\varepsilon) / \mathrm{d}_{\mathrm{cp}}$. При объемной доле жидкости $\varepsilon=0,3$ и $\mathrm{d}_{\mathrm{cp}}=10^{-4} \mathrm{M} \mathrm{a}=$ $=42 \cdot 10^{-3} \mathrm{~m}^{-1}$ и Ка $=3 \cdot 10^{-2} \mathrm{c}^{-1}$. На основе поисковых опытов и решения уравнения (9) возможно рассчитать ректификационную колонну концентратора Д 2 О.

Ниже приведен пример расчета такой колонны с диаметром 0,45 м (в комплексе с опытным вымораживающим опреснителем производительностью 12 т талой вод/сут), зачерпывающим шнеком в своей нижней части лед в количестве $\mathrm{C}=0,146$ кг/с. Согласно расчету в такой колонне из природной воды ожидается получение 0,4896 кг дейтерия/сут (при коэффициенте разделения $\left.\alpha_{\mathrm{i}}=1,255\right)$ в виде 0,49206 кг 99,5\%-ного концентрата дейтерия/сут. За год получим 0,4896 кг.365 = 178,7 кг дейтерия/год. Для опреснителя В 1000 т/сут. получим дейтерия $178,7 \cdot 1000 / 12=14891,6$ кг/год или 14,89 т/год.

В качестве примера на рисунке 4 приведена схема вымораживающего опреснителя-разделителя (ВОР-1000) для переработки йодо-бромной рапы из скважины на юге Херсонской области (ее состав, $\%$ мacc.: $\mathrm{I}_{2}=0,00435, \mathrm{Br}_{2}=0,0154, \mathrm{Na}+\mathrm{K}=1,7295$ (причем, $\mathrm{Na}=1,3, \mathrm{~K}=0,4295), \mathrm{Ca}=0,1336, \mathrm{Mg}==0,0327, \mathrm{Cl}$ $=2,9898, \mathrm{HCO}_{3}=0,0134, \mathrm{SO}_{4}=0,0006, \mathrm{~B}_{2}=0,00552, \mathrm{NH}_{4}$ $=0,015$. Всего солей $\sum=4,94 \%$, воды $=95,06 \%$.

Технология ВОР описана в [9-11]. Исходная рапа охлаждается в $\mathrm{T}_{1}$, затем последовательно в И-Л $\rightarrow$ И$\Omega_{1} \rightarrow$ И-Л $\rightarrow$ И-Л 2 , кристаллизуя в Б рец 0,1,2,3 по мере понижения температуры лед и соли. В этих же баках эти две твердые фазы разделяются вследствие разности плотностей. Соли выводятся из баков, осушаются в сепараторах $\mathrm{CC}_{0,1,2,3}$ и в сухом виде выводятся из установки, а лед отделяется от рассола и промывается от рассольной пленки в СПК. На выходе из СПК в ее верхней части этот уже чистый лед захватывается шнеком РК и поднимается вверх, противоточно 
Ток незеотропной смеси хладоагентов $\mathrm{I}-\mathrm{I}_{3} \rightarrow \mathrm{I}-\mathrm{I}_{2} \rightarrow \mathrm{I}-\mathrm{I}_{1} \rightarrow \mathrm{H}-\mathrm{I}_{0}$

Ток йодо-бромногорассола $\mathrm{I}-\mathrm{I}_{0} \rightarrow \mathrm{I}-\mathrm{I}_{1} \rightarrow \mathrm{I}-\mathrm{I}_{3} \rightarrow \mathrm{I}-\mathrm{I}_{2}$
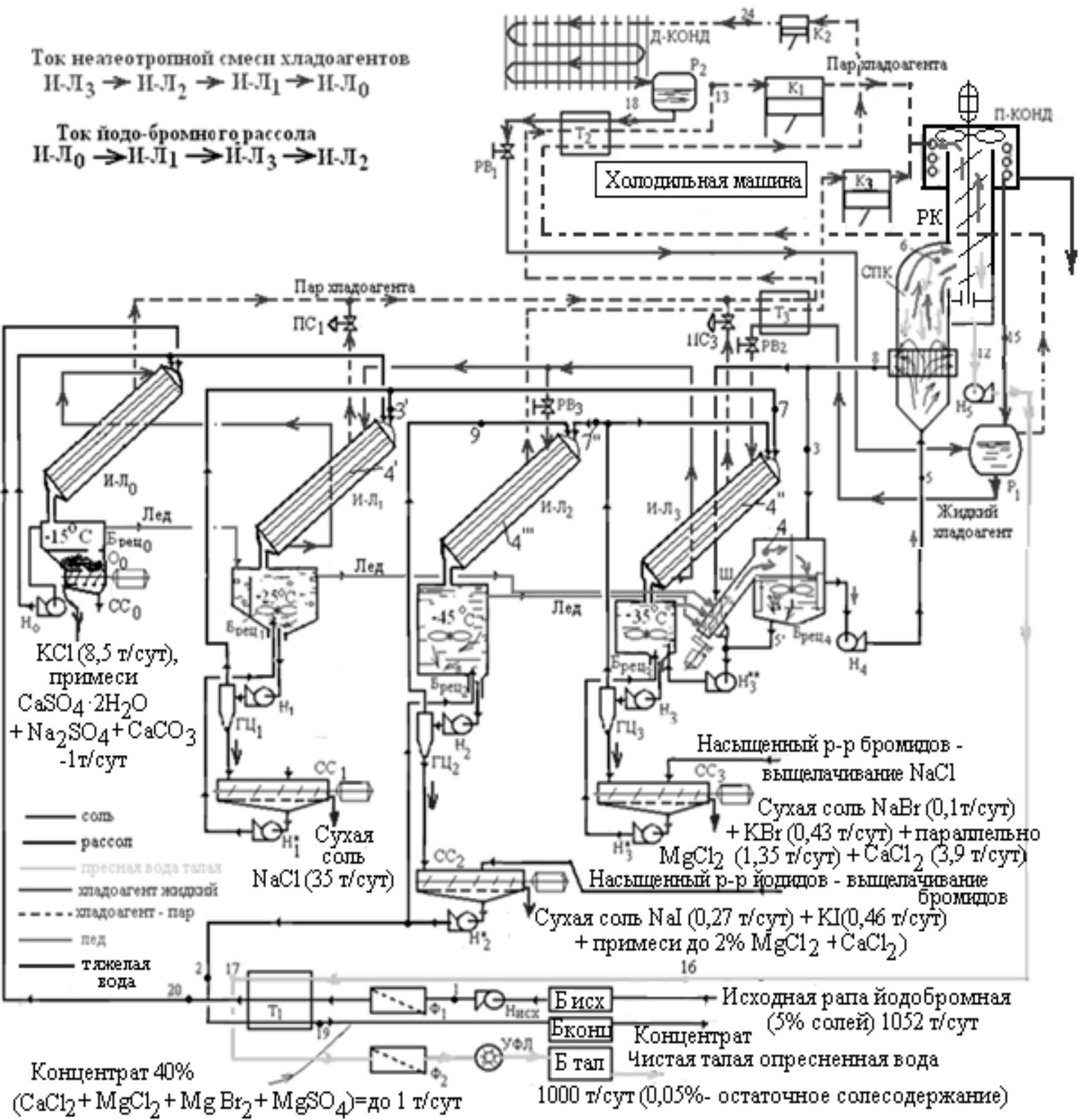

Рисунок 4 - Вымораживающий опреснитель - разделитель йодо-бромного рассола производительностью $1000 \mathrm{~m} / \mathrm{cym}$ по опресненной талой облегченной воде (ВОР-1000), около 1,31 m/cym солей йода и брома и 14,89 $m$ дейтерия/год (74,45 m тяжелой водыl/год).

$Б_{\text {исх, }}, Б_{\text {кони, }}, Б_{\text {тал }}-$ баки исходной рапы, талой воды, концентрата, $Б_{\text {реи 1,2,3,4 }}$-баки рециркулячиионные для роста кристаллов льда и солей, И-Л $1_{0,1,2,3}$ - испарители-льдогенераторы, $C C_{0,1,2,3}$ - сепараторы солей непрерывного действия, $O_{0^{-}}$отстойник солей, $K_{1,2,3}$ - компрессоры холодильные, H- насосы, Ш-шнек ледяной массы, СПКсепарационно-промывочная колонна, РК- ректификационная колонна, П-КОНД-плавитель льда-конденсатор хладоагента, Д-КОНД-дополнительный конденсатор, $P_{1,2}-$ ресиверы жидкого хладоагента, $T_{1,2,3^{-}}$

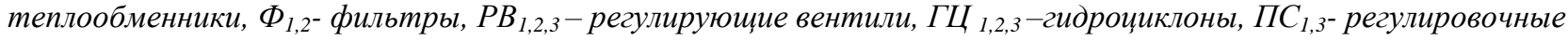
вентили давления «после себя», УФЛ- ультрафиолетовая лампа.

контактируя со стекающей вниз тяжеловодной флегмой. На верхней части РК тяжеловодный лед плавится в П-КОНД, часть тяжелой воды отбирается как продукт (концентрация дейтерия в водородном составе не менее 99,5\%), а основная часть стекает вниз как флегма. Из нижней части РК отбирается уже облегченная чистая талая питьевая вода.

PK - аппарат несложный, это колонна со шнеком, электродвигателем и конденсатором хладоагента (рис. 4). Почти все энергетические и капитальные 
затраты на РК и процесс в ней уже сделаны после монтажа ВОР-1000.

Пример расчета одноступенчатой колонны при производстве дейтерия с концентрацией $\mathrm{Y}_{\mathrm{e}}=\mathbf{9 9 , 5 \%}$

- Принятый коэффициент разделения $\alpha_{i}=1,255$.

- Диаметр колонны $D^{\prime}=0,45$ м.

- Высота колонны $\mathrm{h}=1,917 \mathrm{M}$.

- Диаметр вала шнека $\mathrm{d}=0,05 \mathrm{~m}$.

- Шаг витков шнека $\mathrm{s}=0,25 \mathrm{M}$.

- Количество витков шнека $\mathrm{n}=7,67$.

- Коэффициент диффузии D =0,16·10 $\mathrm{m}^{2} /$.
- Коэффициент массопередачи Ка $=3 \cdot 10^{-2} \mathrm{c}^{-1}[5]$.

- Производительность по воде, вошедшей в лед C=0,146 кг/с-учтен плюс 5\% на промывку в СПК (12 т/сут.).

- Пористость ледяной массы, подпрессованной перемещением ее вверх шнеком $\varepsilon=0,3$.

- Концентрация дейтерия в исходной воде $\mathrm{Y}_{\mathrm{F}}=$ $=0,16 \cdot 10^{-3}$ кг дейтерия/кг исходной воды (0,016\%), $\mathrm{Y}_{\mathrm{F}}=\mathrm{Y}_{\phi}$.

Примем концентрацию дейтерия в обогащенном продукте $Y_{\mathrm{e}}=0,995 \mathrm{\kappa г}$ дейтерия/кг концентрата $(99,5 \%)$.

\begin{tabular}{|c|c|}
\hline $\begin{array}{l}\text { 1. Средний диаметр кольце- } \\
\text { вого пространства РК }\end{array}$ & $d c p=\frac{D^{\prime}-d}{2}+d=\frac{D, 45-D, 05}{2}+0,05=0,25 \mathrm{M}$ \\
\hline $\begin{array}{l}\text { 2. Длина винтовой траектории } \\
\text { движения льда }\end{array}$ & $z=\pi d c p n=3,14 \cdot 0,25 \cdot 7,67=6,021 \mathrm{M}$ \\
\hline $\begin{array}{l}\text { 3. Площадь поперечного се- } \\
\text { чения движения льда }\end{array}$ & $\mathrm{A}=\frac{D^{\prime}-\frac{d}{2}}{2} \cdot s=\frac{\mathrm{D}, \mathrm{A5}-\mathrm{D}, \mathrm{D} 5 \mathrm{5}}{2} \cdot 0,25=0,05 \mathrm{M}^{2}$ \\
\hline $\begin{array}{l}\text { 4. Минимальный расход ис- } \\
\text { ходной воды для извлечения } \\
\text { j=1 кг чистого изотопа }\end{array}$ & $\mathrm{G}_{\min }=\frac{j}{v_{\mathrm{F}} \cdot\left(\alpha_{\mathrm{i}}-1\right)}=\frac{1}{\mathrm{0,00016(1,255-1)}}=24509,8$ кг исходной воды $/ \mathrm{kг} \mathrm{дейтерия}$ \\
\hline $\begin{array}{l}\text { 5. Производительность рек- } \\
\text { тификационной колонны РК } \\
\text { по дейтерию }\end{array}$ & 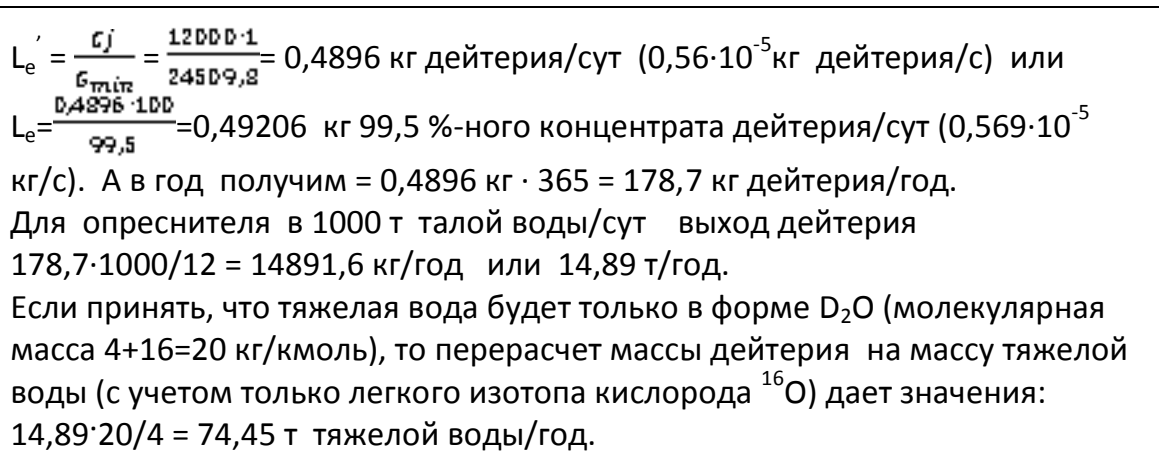 \\
\hline $\begin{array}{l}\text { 6. Концентрационный член } \\
\text { уравнения (9) }\end{array}$ & $Y_{p}=\frac{L_{\varepsilon} Y e}{C\left(\alpha_{i}-1\right)+i_{p}}=\frac{0,569 \cdot 10^{-5} \cdot 0,995}{0,146(1,255-1)+\left[, 569 \cdot 10^{-5}\right.}=0,00015204$ кг дейтерия/кг исх. воды. \\
\hline $\begin{array}{l}\text { 7. Коэффициент сепарации } \\
\text { согласно уравнению (10) }\end{array}$ & $\begin{array}{l}-H=\frac{1}{C\left(\alpha_{i}-1\right)+i_{p}}\left[D \rho A \varepsilon+\frac{\alpha_{i} C\left(C-i_{p}\right)}{\left.K_{Q A P}\right)}\right]=\frac{1}{D, 146(1,255-1)+D, 569 \cdot 1 D^{-5}} . \\
{\left[0,16 \cdot 10^{-3} \cdot 1080 \cdot 0,05 \cdot 0,3+\frac{1,255 \cdot D, 146\left(D, 146-0,569 \cdot 1 D^{-5}\right)}{3 \cdot 10^{-2} \cdot 0,05 \cdot 108 D}\right]=0,513 \mathrm{M}}\end{array}$ \\
\hline $\begin{array}{l}\text { 8. Концентрация дейтерия в } \\
\text { воде на верхнем срезе колон- } \\
\text { ны }\end{array}$ & $\begin{array}{l}Y=\left(Y_{\phi}-Y_{p}\right) \exp [-(z /-H)]+Y_{p}=(0,00016-0,00015204) \cdot e^{\frac{6.021}{0.513}}+0,00015204= \\
=0,99466 \text { кг дейтерия/кг концентрата или } 99,46 \% .\end{array}$ \\
\hline
\end{tabular}

\section{3. Выводы}

1. Вымораживание можно использовать для получения тяжелой воды. Выгодно производство тяжелой воды осуществлять из льда вымораживающего опреснителя, на получение которого уже израсходованы энерго- и капзатраты. Затраты энергии на опреснение в вымораживающем опреснителе $\left(\ell_{\text {опр }}\right.$ $=10$ кВт-ч/ т опресненной талой воды) + затраты на PK (на работу шнека - пренебрегаем) составляют:

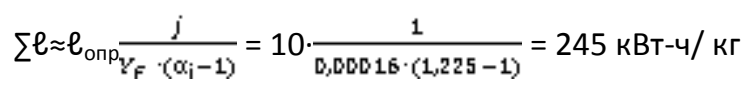

дейтерия или 245/5= 49 кВт-ч/кг тяжелой воды в форме $\mathrm{D}_{2} \mathrm{O}$. Затраты в вымораживающем опреснителе - разделителе будут примерно в 2 раза выше (около 490 кВт-ч/ кг дейтерия и 100 кВт-ч/кг тяжелой воды в форме $\mathrm{D}_{2} \mathrm{O}$ ). Эти значения в несколько раз меньше, чем в существующих ныне промышленных 
технологиях производства тяжелой воды ( 800 кВтч/кг $\mathrm{D}_{2} \mathrm{O}$ и более).

\section{Литература}

1. Смирнов Л. Ф., Дяченко В. К., Першин А. С. и др. Поисковые исследования газогидратного способа обогащения воды тяжелой водой//ЖПХ, 1989. Т.62, №7, c. 1479-1484.

2. Albertins R., Powers J. E. (1969). Am. Inst. Chem. Eng. J., Vol. 15. No. 4 (July), 554-559.

3. Henry J. D., Powers J. E. (1970). Am. Inst. Chem. Eng. J., Vol. 16. No. 6 (November), 1055-1064.

4. Bates C., Gladwin R. P., Grath L. (1977). Desalination, Vol. 21, 83-97.

5. Gates W. G, Powers J. E. (1970). Am. Inst. Chem. Eng. J, Vol. 16, No. 4 (July), 648-658.

6. Hakuta T., Goto T., Jshizaka (1978). Desalination, Vol. 25, 61-69.
7. Казавчинский я. 3. и др. Тяжелая вода (теплофизические свойства). - М. Госэнергоиздат, 1963. C. 255.

8. Смирнов Л. Ф. О колоночной кристаллизации при концентрировании тяжелой воды газогидратным методом. // ЖПХ, 1992. - Т. 65, Вып. 1. - С. 138-144.

9. Смирнов Л.Ф. Спосіб обробки водних розчинів багатоступеневим виморожуванням та багатоступеневий пристрій для його здійснення. Патент України № 53239 від 11.06.2007.

10. Смирнов Л. Ф. Способ опреснения воды кристаллизацией и устройство для его осуществления. А.с. СССР №1795583 от 10.08.90.

11. Смирнов Л. Ф., Денисов Ю. П. Разработка эффективных испарителей-кристаллизаторов для вымораживающих опреснителей. - Холодильна техніка і технологія, №5. - 2006. - С. 61-65.

Отримана в редакції 15.12.2016, прийнята до друку 07.02.2017

\title{
Technology of Heavy Water Production by Freezing
}

\section{F. Smirnov}

Odessa National Academy of Food Technologies, 112 Kanatnaya str., Odessa, 65039, Ukraine

\begin{abstract}
The freezing technology for producing heavy water is proposed. The technology is based on a significant coefficient of hydrogen isotopes separation in the process of freezing. The principle of column crystallization and melting of ice along the height of the distillation column is used, which makes it possible to obtain a high concentration of deuterium at a still not very high column height. The physical and mathematical models of the column crystallization are considered with the determination of the method for calculating the deuterium concentration along the height of the column. The technology is particularly promising in combining the production of heavy water with desalination-separation of salt water by freezing, when already obtained pure ice desalination is used in the heavy water concentrator even before its melting. This significantly reduces the energy and capital costs of its production.
\end{abstract}

Key words: Deuterium; Heavy water; Freezing; Desalination.

\section{References}

1. Smirnov L. F., Dyachenko V. K., Pershin A. S. (1989). Poiskovyie issledovaniia gazogidratnogo sposoba obogascheniia vody tyazheloi vodoi. ZhPH, Vol.62, No. 7, 1479-1484 (in Russian).

2. Albertins R., Powers J. E. (1969). Am. Inst. Chem. Eng. J., Vol. 15. No. 4 (July), 554-559.

3. Henry J. D., Powers J. E. (1970). Am. Inst. Chem. Eng. J., Vol. 16. No. 6 (November), 1055-1064.

4. Bates C., Gladwin R. P., Grath L. (1977). Desalination, Vol. 21, 83-97.

5. Gates W. G, Powers J. E. (1970). Am. Inst. Chem. Eng. J., Vol. 16, No. 4 (July), 648-658.

6. Hakuta T., Goto T., Jshizaka (1978). Desalination, Vol. 25, 61-69.

7. Kazavchinskiy Ya. Z. (1963). Tiazhelaia voda (teplofizicheskie svoistva). M. Gosenergoizdat, 255 p. (in Russian).
8. Smirnov L. F. (1992). O kolonochnoi kristallizatsii pri kontsentrirovanii tiazheloi vody gazogidratnym metodom. ZhPH, 65(1), 138-144 (in Russian).

9. Smirnov L. F. Sposlb obrobki vodnih rozchinlv bagatostupenevim vimorozhuvannyam ta bagatostupe-neviy pristrly dlya yogo zdlysnennya. Patent UkraYini No.53239 vid 11.06.2007 (in Ukrainian).

10. Smirnov L. F. (1990). Sposob opresneniya vodyi kristallizatsiey i ustroystvo dlya ego osuschestvleniya. A.s. SSSR No.1795583 ot 10.08.90 (in Russian).

11. Smirnov L. F., Denisov Yu. P. (2006). Razrabotka effektivnykh isparitelei-kristallizatorov dlia vymorazhivaiuschikh opresnitelei. Refrigeration Engineering and Technology, No. 5, 61-65 (in Russian).

Received 15 December 2016 Approved 07 February 2017 Available in Internet 17 March 2017 